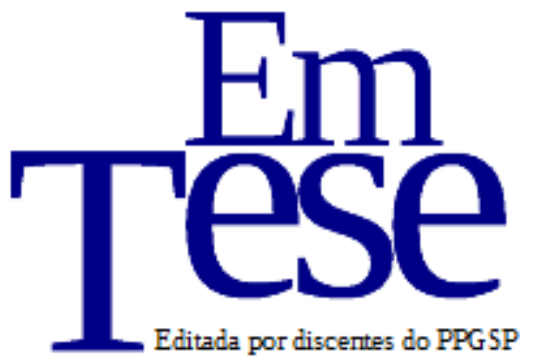

UFSC

PPG SP PROG RAMA DE

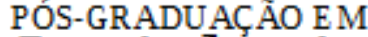

Sociologia

Política

v. 15, n. 1 (parte II), p.03-09, mar./abr., 2018.

http://dx.doi.org/10.5007/1806-5023.2018v15n1p3

\title{
APRESENTAÇÃO ${ }^{1}$
}

\section{Pensamento político brasileiro: o vigor de um campo de pesquisa}

\author{
Vera Alves Cepêda ${ }^{2}$ \\ Josnei Di Carlo ${ }^{3}$
}

Iniciando a apresentação do Dossiê Pensamento Político Brasileiro, organizado por nós para a Em Tese, revista editada pelos(as) discentes do Programa de Pós-Graduação em Sociologia Política (PPGSP) da Universidade Federal de Santa Catarina (UFSC), destacamos o recebimento de um conjunto significativo, maduro e refinado de artigos que revelam o contorno deste campo de pesquisa. Como resultado da chamada para composição do Dossiê podemos inferir tanto o vigor constante de pesquisa presente nesse campo de estudos quanto o interesse das novas gerações de pesquisadores, indicado pela presença de muitos dos trabalhos presentes nestes dois volumes da Em Tese.

Destacamos este elemento geracional em função de dois argumentos. O primeiro versa sobre a longevidade dos estudos sobre o pensamento político brasileiro (PPB), que antecedem a própria institucionalização da Ciência Política no Brasil. É no contexto desta trajetória longa que se aninha o interesse de pesquisa sobre a produção intelectual de autores, escolas, obras, temas e agendas de problemas que atravessaram fases diferentes da vida pública e acadêmica brasileira, oscilando entre o engajamento político, a interpretação da identidade nacional, o protagonismo da intelligentsia, o autor-ator ou o statemaker e os efeitos políticos das ideias, de um lado, ou da reflexão mais especificamente organizada academicamente sobre os cânones e condições da produção intelectual brasileira, por outro. $\mathrm{O}$ segundo argumento assenta sobre o potencial em aberto dos estudos da área, em função de sua própria estruturação metodológica: a ressignificação, o diálogo duradouro e os efeitos reposicionados que as formulações do

\footnotetext{
1 (c)) EY Esta obra está licenciada com uma Licença Creative Commons Atribuição 4.0 Internacional. ${ }^{2}$ Doutora em Ciência Política pela Universidade de São Paulo (USP). Professora do Programa de Pós-Graduação em Ciência Política (PPGPol) da Universidade Federal de São Carlos (UFSCar). E-mail: cepeda.vera@gmail.com.

${ }^{3}$ Doutorando do Programa de Pós-Graduação em Sociologia Política (PPGSP) da Universidade Federal de Santa Catarina (UFSC). E-mail: josneidicarlo@ hotmail.com.br.
} 
pensamento político assumem. Neste caso, a exigência analítica de compreensão do contexto de emergência de uma formulação/tese pode ser modificada pela dilatação temporal, reposicionando a compreensão de uma determinada tese (apreendendo-a de outro ponto de vista e com outra função ou efeito social), quanto modificando a explicação das condições históricas de sua origem (neste caso produzindo outro entendimento sobre o momento epocal). Neste processo de constante modificação das compreensões é possível capturar as nuances da relação contexto histórico versus teses, revelando as nuances políticas de um momento e a sucessão de suas contínuas ressignificações. Parte da luta política abriga-se nestes constantes deslocamentos, ponto de partida para a contínua atualização dos estudos da área de pensamento político.

Somadas, as duas tendências - longevidade e atualização constante - explicam a permanência de temas e autores do pensamento brasileiro como objeto de estudo de várias gerações. Um último ponto a acrescentar é sobre o potencial subjacente contido no campo do PPB na detecção das gramáticas políticas nacionais, cruzando a recepção e diálogo das matrizes internacionais com as condições do contexto brasileiro. Neste sentido, pesquisar as matrizes e tessituras do pensamento político nos permite compor o quadro das inclinações e ajustes da cultura política nacional que funcionam, como parte importante da concepção de mundo e valores sociais, da orientação da ação e da modelagem das instituições.

Feita esta introdução geral, tentamos agora um exercício de organização temática e filiações institucionais dos artigos apresentados nos dois volumes deste Dossiê.

Seus 16 artigos foram subdivididos em duas partes, conciliando contexto histórico e temas. O critério fica nítido através dos sumários, com sua organização cronológica às vezes formando blocos temáticos, com poucas exceções - dois deles, pelo seu caráter epistemológico ou comparativo, um abrindo a primeira parte do Dossiê e outro a encerrando. A segunda parte abre com um de método comparativo, ajustado à ordem cronológica a ser seguida - do Século XIX ao XXI. Julgamos que essa distribuição confere organicidade ao Dossiê, independentemente da ampla e rica variação de temas e problemas abordados pelo conjunto dos artigos.

Tomando o Dossiê como uma amostra de um campo de estudos, podemos refletir sobre o estado da arte do interesse e da produção intelectual no campo do PPB. São 16 artigos publicados de um total de 27 recebidos - avaliados por 62 pareceristas, distribuídos por 34 instituições de ensino superior (IES). Levando em conta o tema dos artigos e o IES dos autores da Tabela 1, podemos inferir sobre os grupos de estudo do PPB a partir de seus principais referenciais teóricos conforme Lynch (2016), Karl Mannheim, György Lukács e Antonio Gramsci); avançando, com a análise das referências bibliográficas usadas nos 16 artigos, para questões teóricas e metodológicas do campo. 
Tabela 1: Dossiê Pensamento Político Brasileiro da Em Tese

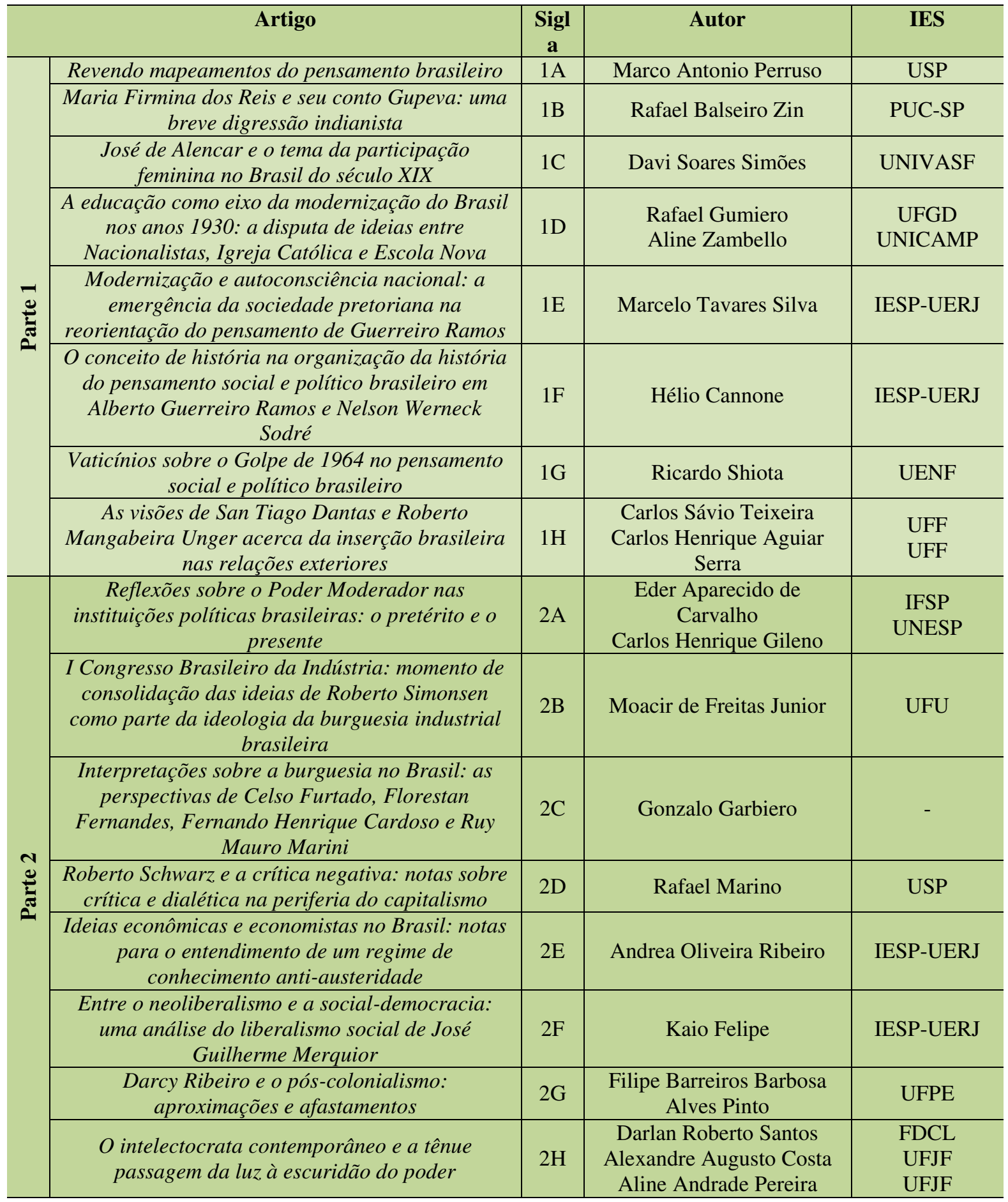

No conjunto dos artigos destaca-se a presença das abordagens mannheimianas, lukacsianas e gramscianas, identificadas com programas e linhas de pesquisa institucionalizadas. A prevalência da primeira abordagem encontra-se nos programas de pós-graduação do Instituto de Estudos Sociais e Políticos da Universidade Estadual do Rio de Janeiro (IESP-UERJ) e da Universidade Federal Fluminense (UFF); a da segunda, Universidade de São Paulo (USP). A terceira abordagem não predomina em um programa, mas se considerarmos os principais nomes citados por Lynch (2016), estão distribuídos nos da Universidade Federal de Juiz de Fora 
(UFJF), Universidade Federal de São Carlos (UFSCar) e Universidade Estadual Paulista (UNESP). Em princípio, todos os grupos estão representados no Dossiê.

Os mannheimianos são tributários do Instituto Superior de Estudos Brasileiros (ISEB), marcados pelos temas do autoritarismo, da democracia e do liberalismo. Dois artigos provenientes do programa do IESP-UERJ são sobre intelectuais do ISEB (1E e 1F), o terceiro sobre um liberal (2F). O quarto e último (2E) parece destoar da temática mannheimiana. Mas a democracia emerge como tema transversal e, em alguns trabalhos (2E é exemplar), em sua tensão com a dimensão econômica. Completa esse cenário, o artigo sobre política externa $(1 \mathrm{H})$ e sobre a crise e percepção de 1964 (1G) - que analisa os prognósticos a respeito da ruptura na ordem democrática em obras anteriores ao Golpe de 1964 (entre os intelectuais analisados aparece a produção de Álvaro Vieira Pinto, Guerreiro Ramos, Nélson Werneck Sodré e Wanderley Guilherme dos Santos). Em tese, a influência teórica de maior destaque nestes seis artigos seria a de Mannheim. Por suas referências apenas o 1F se referencia diretamente em Mannheim, enquanto o 2F indiretamente, através de Christian Edward Cyrill Lynch, do grupo mannheimiano. Mas qual seria a fundamentação teórica dos demais? A do $1 \mathrm{E}$ poderia ser Reinhart Koselleck; do 1G, Mark Bevir. Por sua vez, as referências do 2E giram em torno de seu tema - economia; e as do $1 \mathrm{H}$, de seus objetos - San Tiago Dantas e Roberto Mangabeira Unger. Frequentemente, os artigos do Dossiê trabalham com os autores dos outros grupos que tratam do mesmo tema ou objeto, indicando um intenso diálogo entre os grupos no campo ou predominância da análise textualista.

Mannheim, ademais, é citado em outros três artigos. Por ser epistemológico, o 1A também trabalha diretamente com Gramsci e indiretamente com Lukács, através de pesquisadores lukacsianos. Pela natureza do artigo, a interlocução entre os grupos está em seu cerne. Assim como com alguns fundadores do campo - Bolívar Lamounier, Maria Tereza Sadek, Gildo Marçal Brandão. O 1D, além de citar Mannheim, cita Quentin Skinner; e o 2H, Gramsci. Aparentemente, este, por estar investigando um objeto novo no campo, inserido nas redes sociais, é o que faz uso de referências metodológicas, com obras sobre análise de dados qualitativos, estudo de caso e pesquisa social.

Irradiado pela USP, por causa do papel formativo de Gildo Marçal Brandão, os lukacsianos encontraram abrigo, levando em consideração os pesquisadores do projeto temático Linhagens do Pensamento Político-Social Brasileiro, na Universidade Federal do Rio de Janeiro (UFRJ), na Universidade Federal de São Carlos (UFSCar), na Universidade Estadual de Campinas (UNICAMP) e na Universidade Federal de São Paulo (UNIFESP). Acompanhando o desenvolvimento das pesquisas de Gildo sintetizado por Bastos (2010), os lukacsianos poderiam partir da construção do Estado-nação e de seus intérpretes para construir seus temas. $\mathrm{O}$ artigo 
citado anteriormente 1A, ao sugerir novas categorias para mapear o campo, interage com Gildo, entre outros que pensaram as tradições do PPB. Tomando a educação como eixo da modernização do Estado (1D) ou Roberto Schwarz como intérprete do Brasil (2D), eles corroboram a percepção de Lynch (2016) dos dois ramos do grupo lukacsiano: um de leitura não marxista - resultando em uma abordagem próxima da mannheimiana - e outro de leitura marxista.

Curiosamente, Lukács é citado diretamente apenas por um dos três artigos. Por ser epistemológico, o 1A é dialógico por excelência, referenciando-se, principalmente, nos lukacsianos (Gildo Marçal Brandão, Bernardo Ricupero, Roberto Schwarz), em Gramsci e nos gramscianos (Luiz Werneck Vianna) e em Mannheim. Como já apontado anteriormente, o 1D trabalha com Mannheim e Skinner. Finalmente, o 2D é o artigo que cita diretamente Lukács, trabalhando com uma plêiade marxista, de Karl Marx a Perry Anderson, passando por Walter Benjamin e Theodor W. Adorno, e com os lukacsianos do PPB (Michael Löwy, Bernardo Ricupero). Os lukacsianos não marxistas talvez caminhem para a integração ao grupo mannheimiano, tornando-o, futuramente, ainda mais hegemônico no campo, como inferimos ao tomarmos o Dossiê como uma amostra do campo.

Se continuarmos a refletir sobre os temas, talvez possamos incluir mais dois artigos no grupo lukacsiano. O 2B e o 2C, preocupados com a formação da ideologia burguesa e as interpretações sobre o papel da burguesia no Brasil, respectivamente. Pesquisando Roberto Simonsen, a principal referência do primeiro é uma pesquisadora do grupo (Vera Alves Cêpeda). $\mathrm{O}$ segundo referencia-se nos marxistas, destacadamente brasileiros, por analisar Fernando Henrique Cardoso, Florestan Fernandes, Celso Furtado e Ruy Mauro Marini. Poderíamos aproximar este do 2D e aquele do 1A, mas nenhum dos dois citam Lukács diretamente, muito menos Mannheim e Gramsci. Nesse sentido, estão mais próximos do $1 \mathrm{H}$ e 2E, por suas referências girarem em torno de seu tema e/ou objetos. Talvez o objeto estudado oriente a abordagem teórica a ser adotada, se mannheimiana, lukacsiana ou gramsciana; principalmente no caso do pesquisador não ter sido orientado por um dos professores dos grupos.

Sendo o grupo mais capilarizado do PPB, fica mais difícil iniciar nossa reflexão sobre o gramsciano a partir da origem institucional do pesquisador. Por sua origem, o 2A poderia pertencer ao grupo; inclusive foca um período histórico caro aos gramscianos mirando o debate público contemporâneo ao comparar o Poder Moderador do século XIX com o ativismo judiciário do século XXI. Mas o artigo não trabalha diretamente com Gramsci, centrando suas referências nos trabalhos que tratam do mesmo tema, independente da abordagem teórica. Gramsci é citado diretamente apenas em dois artigos (1A e $2 \mathrm{H})$ e sua figura de proa Luiz Werneck Vianna, novamente no $1 \mathrm{~A}$. 
Pelos critérios que consideramos para refletirmos sobre o Dossiê, três artigos $(1 \mathrm{~B}, 1 \mathrm{C}$ e 2G) não se alinham à abordagem de análise que agrupamos os outros. Demostrando, de um lado, os limites de qualquer enquadramento; e, de outro lado, que o PPB é um campo que pode ser explorado com temas que emergem com as novas gerações de pesquisadores. Assim como o 1H, os temas de 1B, 1C e 2G são marginais no campo: o indianismo, a participação feminina e o póscolonialismo, respectivamente. Como observamos para os outros artigos, se o objeto parece orientar a abordagem teórica, quando ele é marginal, acentua-se essa prevalência.

A dificuldade de se precisar a abordagem teórica dos 16 artigos através de suas referências bibliográficas certamente é consequência de um campo interdisciplinar por excelência. Mesmo assim, a abordagem mannheimiana ganha terreno no interior do PPB. Como um "modo de ver", remetendo a conceitos e a categorias fixados por outros autores a serem empregados para examinar determinados fenômenos da realidade (BARROS, 2013), a hegemonia de uma teoria criará gargalos no campo, possivelmente restringindo ainda mais os temas e os objetos investigados pelo PPB.

Para além da teoria, há o método - um "modo de fazer", referindo-se a uma forma "de trabalhar algo, de eleger ou constituir materiais, de extrair algo destes materiais, de se movimentar sistematicamente em torno do tema definido pelo pesquisador" (BARROS, 2013, p. 274). As fontes primárias dos artigos são diversas: anais, conferências, entrevistas, leis, livros, relatórios, textos jornalísticos, assim por diante. Fica a pergunta se eles problematizam suas fontes, na medida em que apenas o $2 \mathrm{H}$ usa fontes secundárias relacionadas diretamente ao meio em que as ideias investigadas circulam. O faz, muito provavelmente, por seu objeto atuar em um espaço público novíssimo - a rede social Facebook, criada em 2004. Restringindo-nos ao suporte clássico do texto, a edição do livro pode alterar a direção do pensamento de seu autor. Passado 40 anos de sua primeira edição, Raízes do Brasil é um caso exemplar. As revisões em sua segunda edição (1948) e terceira (1956) por Sérgio Buarque de Holanda demonstram que um livro não é onde temos a cristalização do pensamento de seu autor (SCHLEGEL, 2014). Por rigor metodológico, quando um livro for fonte primária, deve-se privilegiar a edição princeps, sendo inacessível, um fac-símile. Um problema menor, se tomarmos o Dossiê como uma amostra. Em princípio, não para os outros suportes do texto. Partindo das investigações de Roger Chartier, podemos ampliá-la afirmando que a forma de transmissão do pensamento - se através de uma conferência, uma entrevista, um livro, um relatório ou um jornal - é decisiva para o enunciado, modelando as ideias. Com isso, o método para lidar com a especificidade de cada suporte da obra deve ser refinado pelos pesquisadores do PPB. 


\section{Referências}

BARROS, José D'Assunção. Teoria e metodologia - algumas distinções fundamentais entre as duas dimensões, no âmbito das ciências sociais e humanas. Revista Eletrônica de Educação, São Carlos, v. 7, n. 1, pp. 273-289, mai. 2013.

BASTOS, Elide Rugai. Gildo Marçal Bezerra Brandão (1949-2010): um analista do pensamento brasileiro. Dados, Rio de Janeiro, v. 53, n. 1, pp. 5-10, 2010.

LYNCH, Christian Edward Cyrill. Cartografia do pensamento político brasileiro: conceito, história, abordagens. Revista Brasileira de Ciência Política, Brasília, n. 19, pp. 75-119, jan.-abr. 2016.

SCHLEGEL, Rogerio. As metamorfoses do Estado nas edições de Raízes do Brasil. $38^{\circ}$ Encontro Anual da ANPOCS, Caxambu, out. 2014. Disponível em: $<$ http://www.anpocs.com/index.php/papers-38-encontro/gt-1/gt28-1/9350-asmetamorfoses-do-estado-nas-edicoes 